\title{
(2) Pathogenesis of Hypertensive Diseases
}

\section{- Recent Progress in Studies on Animal Models for Hypertension and Stroke-}

\author{
Yukio YAMORI, MD \\ Department of Pathology, Shimane Medical University \\ Japan Stroke Prevention Center, Shimane
}

\section{INTRODUCTION}

Vrious strains of rats with genetic hypertension such as spontaneously hypertensive rats $(\mathrm{SHR}, 1963)^{1)}$, genetically hypertensive rats of New Zealand strain (1958) ${ }^{2)}$ and Milan strain $(1974)^{3)}$ are now available, and main materials for hypertension research have changed from artificially induced experimental hypertensive animals ${ }^{4-8)}$ to these genetically hypertensive model animals. Especially SHR which develope not only hypertension but also hypertensive complications in the brain, heart and kidney, are regarded as being superior to other models with genetic hypertension which rarely develope cardiovascular diseases. Furthermore, stroke-prone SHR (SHRSP, 1974) ${ }^{9,10)}$ were established from SHR and they nowadays develope stroke more than 90\%. On the other hand, in search model for the better model for atherogenesis in rats, SHR which showed greater reactive hypercholesterolemia had been selected and finally arteriolipidosis-prone rats (ALR, 1976)11) were obtained. They not only develope reactive hypercholesterolemia over 500 and $800 \mathrm{mg} / \mathrm{dl}$ in males and females, respectively, but also arterial fat deposits in small arteries such as mesenteric, cerebral, renal and coronary arteries within a few weeks when fed a hypercholesterolemic diet. Using these SHR, SHRSP and ALR as models for cardiovascular diseases, the pathogenesis and prevention of hypertension, stroke and atherosclerosis can be studied now extensively by various experimental ap- proaches.

\section{PATHOGENESIS of GENETIC HYPERTENSION}

\section{a. Gene-Environment Interaction}

Genetic factors are important in hypertension as proved by the successful development of hypertensive strains by a selective breeding. This hypertension is genetically determined about $80 \%$ by the additive mode of inheritance of at least 3 major genes, among which one is the most potent for causing hypertension ${ }^{12,13)}$. On the other hand, environmental factors such as stress ${ }^{14)}$ and excess dietary salt intake ${ }^{15)}$ augment hypertension and aggravate hypertensive diseases. Thus, hypertensive diseases are caused by a close gene-environment interac tion.

\section{b. Mechanisms of Spontaneous Hypertension}

Miscellaneous experiments in SHR have indicated that neurogenic mechanisms are very active in the initial stage of hypertension ${ }^{17-21)}$ but become not so marked when hypertension is established. The imbalance of the central regulation of blood pressure between pressor and depressor mechanisms is presumed to be involved in the development of spontaneous hypertension as indicated by abnormalities of enzymes related to the metabolism of neurotransmitters in the brain ${ }^{22-26)}$.

At the initial stage when neurogenic components are predominant, vascular alteration such as constriction and dilatation is functional and reversible, but becomes organic and irreversible when 
hypertension persists for several months ${ }^{27)}$. Amino acid incorporation into collagenous and noncollagenous proteins in aorta and mesenteric arteries is increased already one month after the development of hypertension (adaptive metabolic change) ${ }^{20,28)}$ Although the acceleration of vascular collagen synthesis is secondary to hypertension, that of noncollagenous protein synthesis is not only secondary to hypertension but also directly influenced by the increased sympathetic tone in the pre-or early hypertensive stage (neurovascular linkage ${ }^{19,29)}$. Thus hypertension, directly through neurogenic tone or indirectly through pressure load, induces the acceleration of collagen and noncollagenous protein synthesis which results in arteriosclerosis and adaptive structural changes, increasing the peripheral vascular resistance and finally fixing the hypertension itself.

\section{PATHOGENESIS OF STROKE}

\section{a. Risk Factors of Stroke}

Analyses on the relation between blood pressure and stroke in more than 2000 SHRSP have revealed that severe hypertension over $200 \mathrm{mmHg}$, especially that develops quickly in younger age, is one of the major risk factors of stroke ${ }^{10)}$. SHRSP have been further separated into 2 substrains; SP-1 develop severe hypertension in younger age and die of stroke (hemorrhage: $\operatorname{infarction}=1:$ 1) before 300 days, while SP-2 develop severe hypertension gradually and mostly die of cerebral thrombosis over the age of 300 days (spontaneous thrombogenic rats, STR, $1978)^{30)}$. The impairment of fibrinolytic systems in SHRSP and these new models was confirmed to be one of the causes of cerebral thrombosis ${ }^{31}$.

\section{b. Mechanisms of Stroke}

The common angioarchitectural characteristics in the predilection sites of stroke in SHRSP as well as in man was proved to be recurrent branchings ${ }^{32)}$. When hypertension surpasses $200 \mathrm{mmHg}$, regional ce- rebral blood flow (rCBF) to the brain area fed by recurrent arteries branching off from the main arterial stream decreases down to $50 \%$ of the control values ${ }^{33)}$. Such a chronic reduction of $\mathrm{rCBF}$ increases vascular permeability due to hypoxia and induces arterionecrosis by the insudation of plasma. When the necrotic arterial walls or microaneurysms formed there rupture, hemorrage occurs. On the other hand, multiple thrombosis at arterionecrotic walls, microaneurysms or narrowed arteries, is the cause of cerebral infarction. Thus, these cerebrovascular lesions in SHRSP are defined as arterionecro-thrombogenic stroke ${ }^{34)}$.

\section{c. Possible Involvement of Central Amines} Fluorescence microscopic studies showed that catecholamine fluorescence was depleted in the predilection sites of cerebrovascular diseases in the brain of SHRSP at the advanced stage ${ }^{35)}$. Also experimental CBF reduction by bilateral carotid artery ligation in young SHRSP depleted central catecholamine which sometimes appeared accumulating at small intracerebral vessels, suggesting that released catecholamine from central aminergic neurones under hypoxia might further accelerate vasoconstriction to reduce $\mathrm{rCBF}$ or increase vascular permeability.

\section{d. Renal Factors}

Renin-angiotensin system is activated in SHRSP at the age of about 5 months and therafter when hypertensive vascular lesions are observed in the kidney and other organs ${ }^{36)}$. This activation may be secondary to renal vascular lesions but the possibility can not be eliminated that increased plasma renin further accelerates cerebrovascular lesion.

Our recent studies indicated that water balance was deviated in SHRSP with the impairment of renal sodium excretion, although both SHRSP and SHRSR showed salt-preference in comparison with WistarKyoto rats when they were given $2 \%$ salt water and tap water simultaneously ${ }^{37}$. 
This impairment was detected in SHRSP only in the prehypertensive stage but no longer observed when hypertension developed, because hypertension itself might accelerate sodium excretion.

\section{"PREVENTIVE PATHOLOGY" of HYPERTENSIVE DISEASES -Dietary Prevention of Stroke-}

One of the contribution of SHR and SHRSP is the promotion of experimental studies not only on the pathogenesis but also the prevention of hypertension and stroke. Although genetic factors are important in hypertensive diseases as shown by the establishment of SHRSP, environmental factors have been proven to affect the development of hypertensive diseases. The following findings indicate that hypertensive diseases can be prevented by modifying environmental factors.

\section{a. Fat Intake}

In SHRSP fed a high-fat-cholesterol (HFG) diet, the incidence of arterionecrothrombogenic stroke was decreased ${ }^{38)}$. This reduction of stroke incidence in these SHRSP was ascribed to the attenuation of severe hypertension, the mechanism of which might be due to the reduction of vascular reactivity to pressor substances in SHRSP fed an HFC diet ${ }^{39}$. These experimental data are consistent with epidemiological findings that the incidence of stroke due to arterionecrosis (not atherosclerosis) is high in Japan where hypertension is not always accompanied with hypercholesterolemia, while myocardial infarction is more preponderant than stroke in western countries where marked hypercholesterolemia is very common in the population.

\section{b. Salt Intake}

Effect of excess salt intake on stroke incidence was greater in SHR substrains with higher spontaneous incidence of stroke, suggesting that stroke-proneness might be closely related to salt metabolism ${ }^{16)}$. In fact, the impairment of salt metabolism was noted in SHRSP in the prehypertensive stage $^{37)}$. Therefore, the early detection of this genetic disposition and the restriction of salt intake in SHRSP as well as in the humans predisposed to stroke are important in the prevention of stroke.

\section{c. Protein Intake}

SHRSP fed a normal (24\%) or low (10\%) protein diet with $1 \%$ salt water for drink developed severe hypertension within a short period and died of stroke in $100 \%$. In contrast, SHRSP fed high $(50 \%$ fish or soybean) protein diets developed hypertension slowly and no stroke was observed ${ }^{40)}$. Even in SHRSP fed the high protein diet with $1 \%$ salt water for drink, the development of severe hypertension somewhat delayed and stroke incidence was markedly decreased ${ }^{33,34,41)}$. These findings indicate that high protein diet prevents the development of severe hypertension and stroke and also attenuates the adverse effect of salt. Although the excess intake of animal proteins attenuated the development of hypertension, plant protein (soybean), without such an effect on blood pressure, still showed a definite preventive effect on stroke $^{34,41)}$. The enough intake of protein from younger age improved the physical characteristics of the arterial walls in SHRSP, which were noted to be more brittle than those in SHRSR or WistarKyoto $^{42)}$. Therefore, the mechanisms for preventing stroke by high protein diet intake may be either the attenuation of severe hypertension or the improvement of the physical characteristics of arterial walls, or both.

\section{CONCLUSION}

The establishment of animal medels for adult cardiovascular diseases such as hypertension, stroke and arterio- or atherosclerosis has enabled us to study experimentally not only on the pathogenesis but also on the prevention of these diseases. Classical pathology is "etiological patho$\log y$ " for mainly studying the pathogenesis 
of diseases, but the establishment of these models contributes to the development of "preventive pathology" which is oriented toward the studies on the methods and mechanisms for preventing diseases.

To realize the prevention of diseases it is indispensable to promote studies on the early detection of the genetic disposition of diseases. In the case of hypertensive diseases, the predisposition may be detectable by checking the tendency to myocardial hypertrophy (unproportional to the blood pressure level $\left.{ }^{43}\right)$, sodium preference, insufficient renal sodium excretion and cardiovascular hyperresponsiveness to stress in the prehypertensive stage. Accumulating experimental findings indicate that hypertensive diseases are predictable and preventable. Diagnosis and therapy of diseases are the medicine for the sick, that is, the medicine of the past and the present. Prescience and prevention of diseases are the medicine for the healthy, that is, the medicine of the future. The establishment of "preventive pathology" in animal models will hopefully contribute to the development of such "preventive internal medicine" for humans from the present diagnostic and therapeutic medicine.

\section{REFERENCES}

1) Okamoto $\mathrm{K}$ and Aoki K: Development of a strain of spontaneously hypertensive rats. Jap Circ J 27 : 282, 1963.

2) Smirk $\mathrm{FH}$ and Hall WH: Inherited hypertension in rats. Nature 182: 727, 1958.

3) Bianchi G, et al: The development of a new strain of spontaneously hypertensive rats. Life Science 14: 339, 1974.

4) Goldlatt H, et al: Studies on experimental hypertension I. Production of persistent elevation of systolic blood pressure by means of renal ischemia. J Exp Med 59: 347, 1934.

5) Grollman A, et al: Role of the kidney in pathogenesis of hypertension as determined by a study of the effects of bilateral nephrectomy and other experimental procedures on the blood pressure. Amer J Physiol 157: 21, 1947.

6) Loomis D: Hypertension and necrotizing arteritis in the rat following renal infarction. Arch Path 41 : 231, 1946.

7) Selye $\mathrm{H}$, et al: Malignant hypertension produced by treatment with desoxycorticosterone acetate and sodium chloride. Canad Med Ass J 49: 88, 1943.

8) Skelton FR: Development of hypertension and cardiovascular-renal lesions during adrenal regeneration in the rats. Proc Soc Exp Biol Med 90: 342, 1955.

9) Yamori Y, et al: Importance of genetic factors in hypertensive cerebrovascular lesions: An evidence obtained by successive selective breeding of stroke-prone and -resistant SHR. Jap Circul J 38 : 1095, 1974.

10). Oakmoto $K$, et al: Establishment of the stroke-prone spontancously hypertensive rat (SHR). Circul Res 34, 35 (suppl 1) : 143, 1974.

11) Yamori Y: Selection of arteriolipidosis-prone rat (ALR). Jap Heart J 18: 602, 1977.

12) Tanase $H$, et al: Genetic analysis of blood pressure in spontaneously hypertensive rats. Jap Circ J 34 : 1197, 1970.

13) Yen TT, et al: A genetic study of hypertension in Okamoto-Aoki spontancously hypertensive rats. Heredity 33: 309, 1974.

14) Yamori $Y$, et al: Augmentation of spontaneous hypertension by chronic stress in rats. Jap Circul J 33 : 399, 1969.

15) Aoki K, et al: Effects of high or low sodium intake in spontaneously hypertensive rats. Jap Girc J 36: 539, 1972.

16) Yamori Y: Hypertensive strains of rats. In Gene-environment Interation in Common Diseases (ed Inoue E, Nishimura H), 141, Univ of Tokyo Press, 1977.

17) Okamoto $K$, et al: Participation of neural factors in the pathogenesis of hypertension in the spontaneously hypertensive rats. Jap Heart J 8: 168, 1967.

18) Nosaka S, et al: Neural fraction of peripheral vascular resistance and vascular reactivity in the spontaneously hypertensive rat. In "Spontaneous Hypertension" (ed Okamoto, K) 67, Springer-Igaku Shoin, New York, Berlin and Tokyo, 1972.

19) Yamori $Y$, et al: Effect of antihypertensive therapy on lysine incorporation into vascular protein of the spontaneously hypertensive rat. Europ J Pharmac 38: 349, 1976.

20) Yamori Y: Contribution of cardiovascular factors to the development of hypertension 
in spontaneously hypertensive rats. Jap Heart J 15: 194, 1974.

21) Nagaoka A and Lovenberg W: Plasma norepinephrine and dopamine- $\beta$-hydroxylase in genetic hypertensive rats. Life Science 19 : 29, 1976.

22) Yamori Y: Neurogenic mechanisms of spontaneous hypertension. In Regulation of Blood Pressure by the Central Nervous System (ed Oneti G, Fernandes M, Kim $\mathrm{KE})$, 65. Grune and Stratton, New York, San Francisco, London, 1976.

23) Yamori $Y$, et al: Norepinephrine metabolism in brainstem of spontanocusly hypertensive rat. Science 170:522, 1970.

24) Nagatsu $T$, et al: Vascular and brain dopamine- $\beta$-hydroxylase activity in young spontaneously hypertensive rats. Science 191:290, 1976.

25) Nagatsu $T$, et al: Dopamine-,- -hydroxylase activity in stroke-prone spontaneously hypertensive rats. Experientia 34 : 305, 1978.

26) Grobecker $\mathrm{H}$, et al: Peripheral and central catcholaminergic neurons in genetic and experimental hypertension in rats. $\mathrm{J}$ Clin Sci Mol Med 51 (suppl 3) : 377, 1976.

27) Yamori Y: Interation of neural and nonneural factors in the pathogenesis of spontaneous hypertension. In The Nervous System in Arterial Hypertension (ed Julius S, Esler M), 17. GG Thomas, Springfield, III., 1976.

28) Yamori Y: Neural and non-neural mechanisms in spontaneous hypertension. Clin Sci Mol Med 51: 431, 1976.

29) Nakada $T$ and Lovenberg $W$ : Lysine incorporation in vessels of spontaneously hypertensive rats: Effects of adrenergic drugs. Europ J Pharmacol 48 : 76, 1978.

30) Yamori Y, et al: Genetic and environmental modification of spontaneous hypertension. Jap Circ J 42, 1978 (in press)

31) Yamori Y, et al: A new model for cerebral thrombosis and its pathogenesis. Jap Heart J 20, 1979 (in press)

32) Yamori $Y$, et al: Pathogenetic similarity of stroke in stroke-prone SHR and humans. Stroke 7: 46, 1976.

33) Yamori $\mathrm{Y}$ and Horie R: Developmental course of hypertension and regional cerebral blood flow in stroke-prone spontaneously hypertensive rats. Stroke 8: 456, 1977.

34) Yamori Y, et al: Pathogenetic approach to the prophylaxis of stroke and atherogenesis in SHR. In "Spontaneous Hypertension" 198, DHEW Publication No. (NIH) 1177, 1977.

35) Yamori Y, et al: Pathogenic mechanism and prevention of stroke in stroke-prone SHR. Progress in Brain Research, 47 (eds de Jong W, Provoost, AP and Shapiro APA) 219 Elsevier, Amsterdam, 1977.

36) Matsunaga $\mathbf{M}$, et al: Plasma renin and vascular lesion in the stroke-prone spontaneously hypertensive rats. Jap Circ J 39 : 1305, 1975.

37) Yamori Y, et al: Electrolyte balance in stroke-prone and -resistant SHR. Jap Heart J 20, 1979 (in press)

38) Yamori Y, et al: Prophylactic trials for stroke in stroke-prone SHR (2). Effects of fat, protein and amino acids. Jap Heart J 18: 551, 1977 .

39) Yamori $Y$ and Horie R : Vascular reactivity in pathological states. In Factors Influencing Vascular Reactivity, (eds Shibata S, Carrier, O), Igaku-Shoin, Tokyo, 1977.

40) Yamori Y, et al: New models of SHR for studies on stroke and atherogenesis. Clin exp Pharm Physiol (supp 3) : 199, 1976.

41) Yamori $Y$ et al: Dietary prevention of stroke in stroke-prone SHR (SHRSP). SaishinIgaku 32: 2256, 1977.

42) Yamori $Y$ and Sasagawa S: Physico-morphological characteristics of aorta in strokeprone and -resistant spontancously hypertensive rats. Jap Heart J 16: 296, 1975.

43) Yamori Y, et al: Vectorcardiographic study on left ventricular hypertrophy in spontaneously hypertensive rats. Jap Circ J 40 : 1315, 1976. 